\title{
Bond strength of porcelain to cobalt chromium dental alloy fabricated by selective laser melting and casting methods
}

\author{
Fariborz Vafaee ${ }^{1}$, Farnaz Firouz1, Parisa Alirezaii ${ }^{2}$, Kusha Gholamrezaii ${ }^{2}$ and Sara Khazaei ${ }^{1 *}$ \\ ${ }^{1}$ Associate Professor, Department of Prosthodontics, School of Dentistry, Hamadan University of Medical \\ Sciences, Hamadan, IR Iran \\ ${ }^{2}$ Assistant Professor, Department of Prosthodontics, School of Dentistry, Shahid Beheshti University of \\ Medical Sciences, Tehran, IR Iran
}

\begin{abstract}
This study aimed to compare the bond strength of porcelain to cobalt-chromium dental alloy fabricatedby selective laser melting (SLM) and casting methods.Twelve rectangular barsmeasuring $25 \times 3 \times 0.5$ mmwere fabricated of cobaltchromium alloy for each of the SLM and casting groupsaccording to IS09693:1999. Porcelain was appliedat the center of each bar measuring $3 \times 8 \mathrm{~mm}$ with $1 \mathrm{~mm}$ thickness. Three-point flexural bond strength test was performed to assess the bond strength of porcelain to alloy. Data were analyzed and compared between the SLM and casting groups via Independent sample t-test (alpha=0.05). Mode of failure was also determined by visual inspection of samples. The mean bond strength of porcelain to SLM alloy $(35.26 \pm 1.22 \mathrm{MPa})$ was significantly higher than that to casting alloy $(33.21 \pm 3.02 \mathrm{MPa})(\mathrm{P}<0.05)$. Most failures in both groups were mixed and no sample showed adhesive failure. The SLM metal-ceramic system showed higher bond strength than the required threshold by IS09693:1999. Compared to alloys fabricated by the casting method, the SLM method showed higher bond strength to porcelain. This relatively new technology is promising for dental application and can serve as a suitable alternative to the conventional casting method for the fabrication of metal-ceramic restorations.
\end{abstract}

KEY WORDS: SHEAR STRENGTH; METAL-CERAMIC; LASER MELTING

ARTICLE INFORMATION:

*Corresponding Author: sarakhazaei_83@yahoo.com

Received 23 $3^{\text {rd }}$ June, 2017

Accepted after revision $24^{\text {th }}$ Sep, 2017

BBRC Print ISSN: 0974-6455

Online ISSN: 2321-4007 CODEN: USA BBRCBA

Thomson Reuters ISI ESC and Crossref Indexed Journal

NAAS Journal Score 2017: 4.31 Cosmos IF: 4.006

๑ A Society of Science and Nature Publication, 2017. All rights reserved.

Online Contents Available at: http//www.bbrc.in/

DOI: $10.21786 / \mathrm{bbrc} / 10.3 / 15$ 


\section{INTRODUCTION}

Metal-ceramic systems for dental restorations are available since the 1960sand the success of metal-ceramic restorations depends on the strength and uniformity of bond at the metal-porcelain interface, which is the most sensitive area in terms of crack formation (Bowers 1985) and (Drummond and et al 1984, Pavlović 2017 and Abduo 2017). Cracks mainly occur at the metal-ceramic interface or within the veneering porcelain (Daftary 1986) and (Zhukovsky 1996). Factors such as trauma, fatigue, occlusal loads and incompatibility between the mechanical properties of metal and porcelain may result in porcelain fracture especially of cohesive type (Pameijer 1996 and Kelsey 2000,Ren 2016 and Kaleli 2017). Metal-ceramic frameworks are conventionally fabricated using the lost wax casting (Anusavice 2003) and (Kaleli 2017).

However, problems associated with casting of base metal alloys such as high melting point, high oxidation potential during casting, time consuming nature of casting and finishing of these alloys, limit their application. Thus, application of a technique to eliminate the casting process may enhance the use of these alloys (Bhaskaran 2013) and (Akova 2008).

The selective laser melting (SLM) technology, also known as the three-dimensional (3D) printing, was introduced for the fabrication of metal copings in metalceramic crowns. This technique does not have many of the limitations of the conventional waxing technique, so thatthe restorations are fabricated by incremental application of $0.02 \mu$ layers (Xin 2012). This technique works based on the computer aided design (CAD) data obtained from the framework design, and uses high temperature laser beams for selective melting of metal framework, which is in the form of powder. The metal framework is formed by incremental addition of these thin layers (Akova 2008).

The success of SLM is related to its ability in fabrication of metal components with complex geometrical shapes from a 3D CAD model. Moreover, this technique can produce components with mechanical properties comparable or superior to those of conventionally fabricated components (Örtorp 2011) and (Quante 2008).Thus, it can be an alternative to the conventional process. Only a few studies have assessed the bond strength of porcelain to alloys fabricated by the SLM technique. Some of these studies have reported superior mechanical properties for copings fabricated by this method and higher bond strength of porcelain compared to those fabricated by the conventional casting method, while some others found no significant difference in bond strength of porcelain between the two groups (Liu YH 2010) and (Wu 2014) and (Ren 2016).
Considering the gap of information and the controversies in this regard, this study aimed to assess the bond strength of cobalt-chromium ( $\mathrm{CoCr}$ ) alloy fabricated by the SLM technique and the conventional wax burnout and casting method.

\section{MATERIALS AND METHODS}

This in vitro, experimental study was conducted on 24 samples (12 fabricated by conventional casting and 12 fabricated by the SLM technique). In the casting group, 12rectangular bars were fabricated measuring 25 $\mathrm{mm} \pm 1 \mathrm{~mm} \times 3 \mathrm{~mm} \pm 0.1 \mathrm{~mm} \times 0.5 \mathrm{~mm} \pm 0.05 \mathrm{mmac}-$ cording to the IS09693-1 (The International Organization for Standardization 2012) using green wax sheets (Berg, Karl Berg GmbH, Engen, Germany). They were spruedand flasked using phosphate-bonded investment material. After wax burnout at $650^{\circ} \mathrm{C}$, melted $\mathrm{CoCr}$ was poured into the space created by wax burnout using a standard broken-arm centrifugal casting machine (Kerr, Orange, CA, USA). Metal sheets were cleaned from investment material and the sprues were cut. Dimensions were adjusted and the thickness of sheets was ensured by a caliper and gauge.

In the SLM group, 12 samples were fabricated with the same dimensions as those in the casting group using EOSINT M270 machine (Manufacturing system; Bego, Bremen, Germany).This device was equipped with ytterbium laser fiber with less than $200 \mathrm{~W}$ laser power, scanning speed of 5-10 mm/second, wavelength of 1060-1100 $\mathrm{nm}$, beam diameter of 100-500 $\mu \mathrm{m}$ and powder feed rate of 5-7 g/minute. Using data obtained from a CAD file with STL format, the device fused metal particles and after scanning each cross-section, the alloy thickness decreased by one layer and a new layer of alloy was applied on the upper surface. This process was repeated until the entire restoration was formed. Table 1 shows the composition of CoCr alloy used for the casting (WBC 9581TM, Bego, Germany) and SLM (EOS Cobalt Chrome SP2; EOSGmbH, Germany) techniques.

The samples in both groups were then subjected to air-borne particle abrasion for five seconds (with 110$250 \mu$ aluminum oxide particles at 3-4 MPa pressure for the SLM alloy and $120 \mu$ aluminum oxide particles at $0.35 \mathrm{MPa}$ pressure for the casting alloy) to provide surface roughness similar to the standard process practiced in the clinical setting. The samples were then cleaned with vapor spray for six seconds. Pre-oxidation was then performed according to the manufacturer's instructionsat $950-980^{\circ} \mathrm{C}$ for five minutes for SLM and $980^{\circ} \mathrm{C}$ for eight minutes for the casting alloy. Air-borne particle abrasion was then performed again and before porcelain application, the samples were cleaned in an ultrasonic 
Table 1. Composition of CoCr alloy used for the casting and SLM techniques according to the manufacturers (wt $\%$ )

\begin{tabular}{l|l|l|l|l|l|l|l|l|l|l|l|}
\hline Group & Co & Cr & Mo & W & Si & Nb & V & Fe & Mn & Ce \\
\hline SLM alloy & 63.9 & 25.3 & 5.2 & 5.5 & 1 & - & - & Max 0.5 & Max 0.1 & - \\
\hline Cast alloy & 61 & 26.6 & 5 & $<2$ & - & - & $<2$ & - & - & $<2$ \\
\hline
\end{tabular}

bath containing 95\% ethanol (Elmasonic, Elma Hans GmbH \&t Co, Koln, Germany) for five minutes.

Next, equal layers of opaque and body porcelain (VMK 95, Vita, Bad Säckingen, Germany) with $8 \mathrm{~mm}$ length, $3 \mathrm{~mm}$ width and $1 \mathrm{~mm}$ thickness $(0.2 \mathrm{~mm}$ opaque porcelain and $0.8 \mathrm{~mm}$ body porcelain) were applied and baked according to the manufacturer's instructions
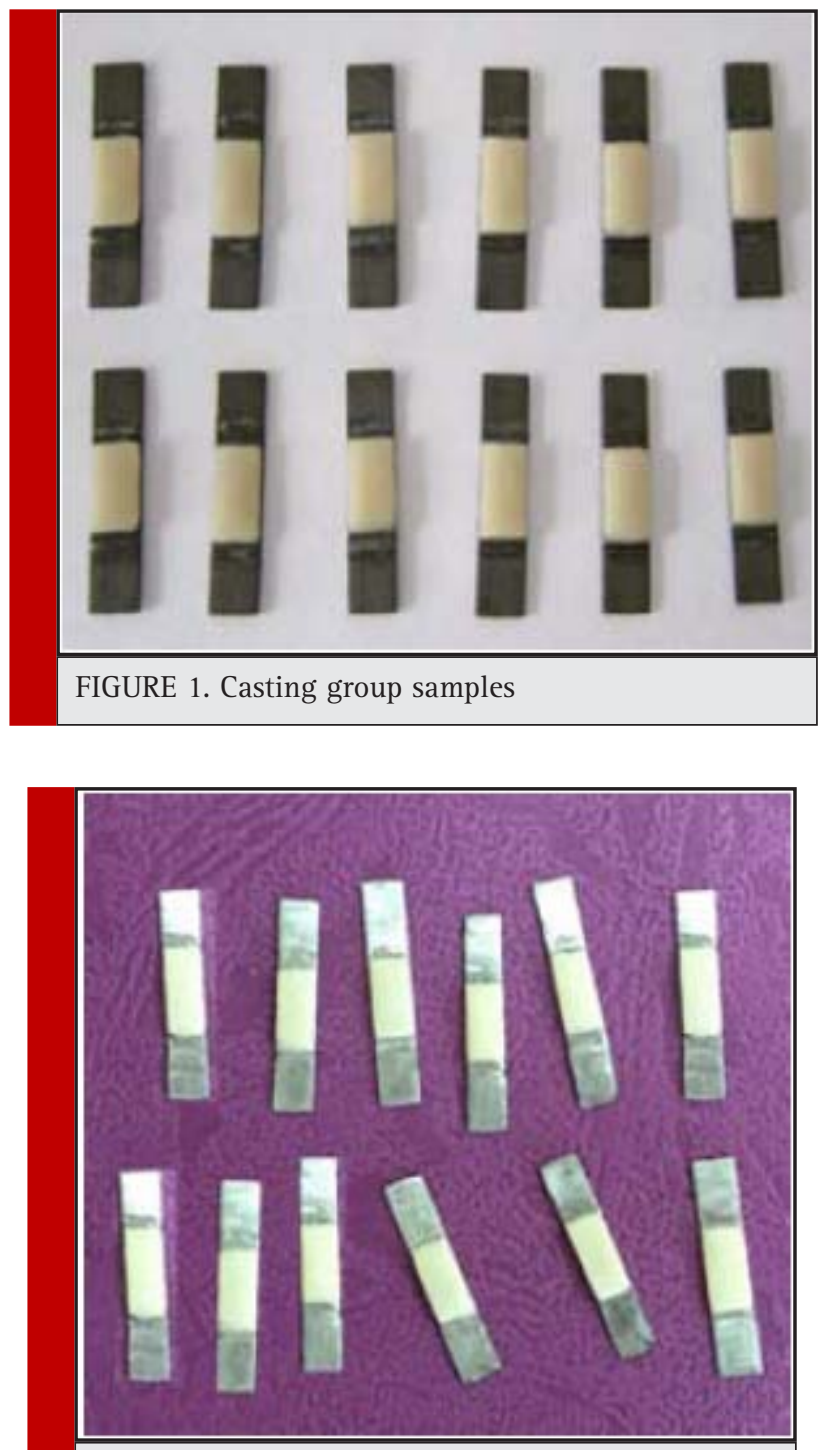

FIGURE 2. SLM group samples
(Figures 1 and 2). For the purpose of standardization of porcelain thickness, a silicon index was used for all samples (Figure 3). To minimize the effect of confounders, all procedures were performed by one operator.

A three-point flexural strength test was performed according to the IS09693-1 standard using a universal testing machine (Z020, Zwick Roell, Germany) .Surface of the sample with porcelain over it was placed downward and the two ends of each rod were placed on the supporting fulcrums with $0.9 \mathrm{~mm}$ diameter and $20 \mathrm{~mm}$ distance from each other. Load was applied to the center of each sample by a crosshead with $0.9 \mathrm{~mm}$ diameter at a speed of $1 \mathrm{~mm} /$ minute(figure 4). Load application was continued until failure (abrupt drop in the stress-strain curve). The load at failure was recorded and reported by the computer. Bond strength in megapascals (MPa) was calculated using the formula $\mathrm{A}=\mathrm{k} \times \mathrm{F}(\mathrm{N} / \mathrm{mm} 2)$ where $\mathrm{k}$
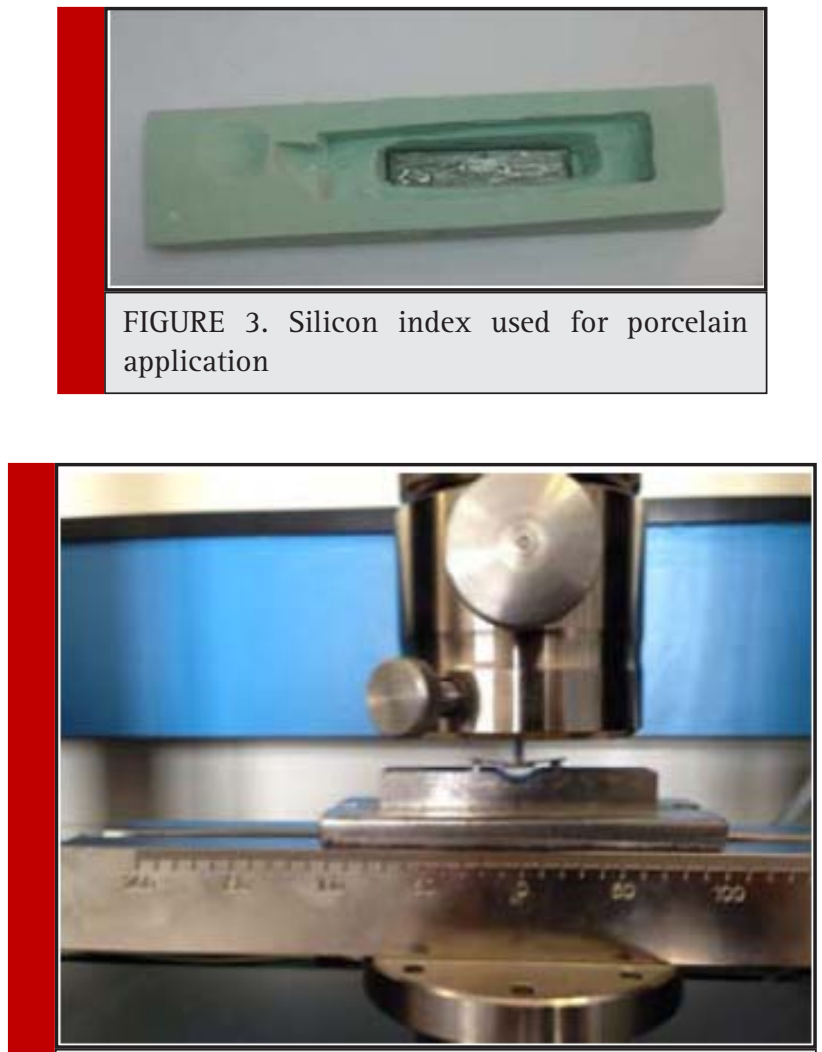

FIGURE 4. Three-point flexural test 


\begin{tabular}{|c|c|}
\hline Group & Mean \pm standard deviation \\
\hline SLM & $35.26 \pm 1.22$ \\
\hline Casting & $33.21 \pm 3.02$ \\
\hline
\end{tabular}

is a constant related to thickness and modulus of elasticity of the alloy and F is the maximum load in Newtons causing debonding.

After conduction of flexural test, the samples were visually inspected to determine the mode of failure. Mode of failure was divided into three groups of adhesive( at the metal-porcelaininterface), cohesive (completely within the porcelain) and mixed (a combination of adhesive and cohesive types).

Finally, Data were analyzed by Independent samples t-test.

\section{RESULTS AND DISCUSSION}

Table 2 shows the mean and standard deviation of bond strength in the two groups.

Independent samples t-test was used to compare the mean values between the two groups, which showed that the mean bond strength of porcelain was significantly higher to alloy in SLM group compared to the casting group $(\mathrm{p}=0.04)$.

Inspection of the surface of samples in the SLM group before porcelain applying showed that the surface of bars in the SLM group was dark gray without metal shine. Figure 5 shows photography of the surface morphology of metal matrix of the one sample of each group after porcelain debonding. Visual inspection of each sample during flexural strength testing showed that debonding cracks between metal and ceramic occurred at one end of the ceramic layer and not at the center.

\begin{tabular}{|l|c|c|c|}
\hline \multicolumn{4}{|c}{ Table 3. Mode of failure in the two groups } \\
\hline Group & $\begin{array}{c}\text { Adhesive } \\
\text { failure }\end{array}$ & $\begin{array}{c}\text { Cohesive } \\
\text { failure }\end{array}$ & $\begin{array}{c}\text { Mixed } \\
\text { failure }\end{array}$ \\
\hline SLM & 0 & 5 & 7 \\
\hline Casting & 0 & 0 & 12 \\
\hline
\end{tabular}

In terms of mode of failure, in the SLM group, most failures were mixed and no adhesive failure was noted. In the casting group, all failures were mixed (Table 3).

\section{DISCUSSION}

Failure of the metal-porcelain bond can occur as the result of a combination of factors such as different coefficients of thermal expansion of metal and ceramic, presence of micro-cracks within the porcelain and occlusal loads or trauma. Loss of porcelain to metal bond is the second most common cause of replacement of metalceramic restorations [18]. The reason for use of SLM technology in this study was the recent introduction of this technique and its numerous advantages. The SLM technique enables the fabrication of restorations with a more uniform quality and standardization of restoration shaping process with lower cost, requiring less human force, saving time due to elimination of many procedural steps (compared to the conventional method) and elimination of human errors. Moreover, CAD, compared to manual waxing, results in more accurate control of the porcelain thickness and decreased risk of fracture. SLM scanners have disadvantages as well including limitation of scanning systems in terms of resolution and creating rounder margins as well as creation of cloudy spots caused by scanning, which result in internal mismatch (Walton 1986) and (Huang 2015) and (Li 2014). High cost of laser device used in this technique is another disadvantage of this method.Also, the CoCr alloy

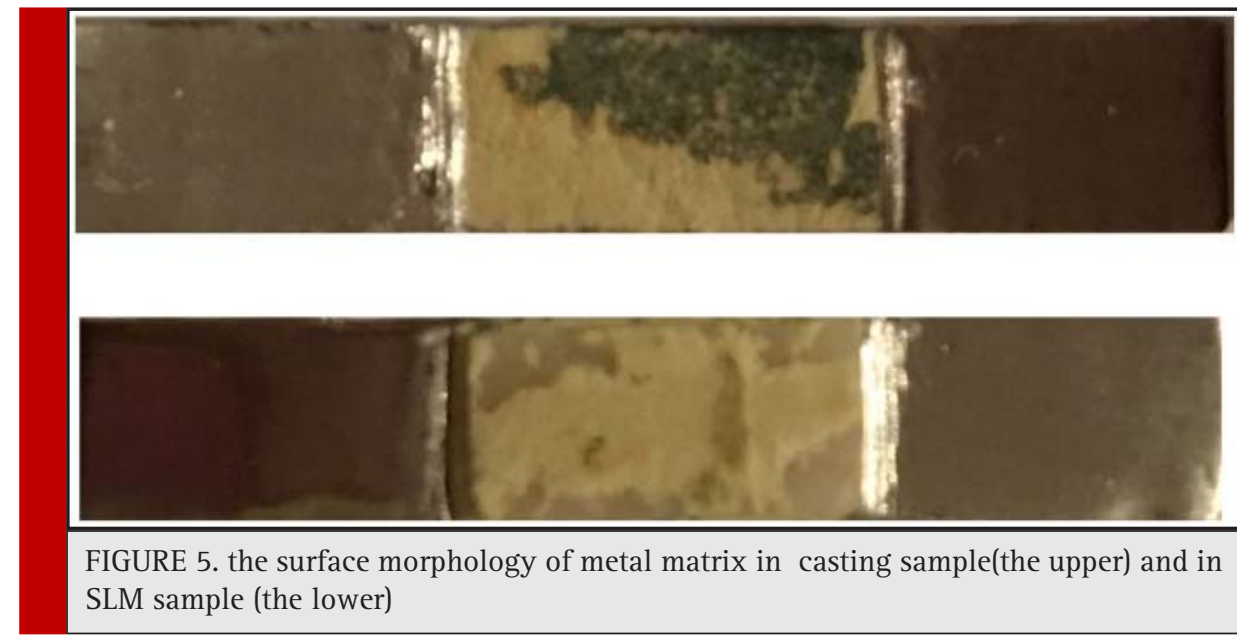


fabricated by the SLM method has not shown any cytotoxic potential and evidence shows that ithas higher corrosion resistance and lower release of cobalt ion compared to the casting group (Xin 2012).

Among the suggested tests for assessment of bond strength, Schwickerath crack initiation test or threepoint flexural strength test was first suggested by Lenz et al, and is alsorecommended by the IS09693:1999(E) for determination of debonding strength of metalceramic systems(Lenz 1995). Although several mechanical tests such as flexural, torsional, shear, tensile or a combination of flexural and shear tests can be used for assessment of the bond strength at the metal-ceramic interface, the validity of the bond strength assessment tests is still questionable (Kontonasaki 2008).

The three-point flexural strength test reveals the modulus of elasticity, flexural strain, flexural stress and flexural stress-strain response of a material. The main advantage of this test is easy sample preparation and conduction. However, it has drawbacks as well. One drawback is that the test result is affected by the geometry of samples, load application and speed of strain application (Kontonasaki 2008). For this reason, in the current study, we tried our best to control for all the confounding factors that had the potential to affect the results such as speed of load application (crosshead speed), distance between the two fulcrums and dimensions of the samples. All samples were fabricated with the same dimensions. Also, a custom-made silicon index was used for control of the length and thickness of ceramic layer when applying the porcelain.

In order to acceptably compare the bond strength of ceramic to metal between restorations fabricate by two different techniques, the materials used should be the same in terms of behavior with regard to the formation of oxide layer, coefficient of thermal expansion, etc. as much as possible (Kontonasaki 2008) and (Zinelis 2003). Therefore, in the current study, alloys with the most similar composition were chosen for SLM and casting groups in order to minimize the effect of elements in the composition of alloys and assess the pure effect of fabrication method on the results .

The bond between the porcelain and metal can be achieved bythree mechanisms of van der Waals forces, mechanical retention and chemical bond; chemical bond is the dominant factor responsible for metal-porcelain bond. Chemical bond is influenced by the composition of elements in the alloy and formation of oxide layer on the metal surface. Due to the significance of the thickness of oxide layer in a successful bond, the pre-oxidation phase of alloy was performed for both groups in our study prior to the addition of porcelainaccording to the manufacturer's instructions (Bagby 1990) and (Jochen 1986).
In this study, the SLM group showed higher porcelain bond strength compared to the casting group, which was in line with the results of Liu et al [14]. One possible reason for higher bond strength of the SLM group was the surface properties of this alloy. The SLM system works based on incremental application of melted powders. The surfaces of fabricated components by the SLM technique often have sticky powder. In other words, relatively melted powders are added to the surface of components and make them rougher (Zhang 2014). Due to the inherent roughness of the surface ofSLM samples and according to the results of a study by Zhang (Zhang 2014), it may be stated that these surfaces can increase the contact area of framework and porcelain. At the same time, surface porosities can provide strong micromechanical retention for porcelain and enhance the bond strength (Zhang 2014).

Another possible explanation is penetration of porcelain into the gaps created between layers as well as the balling phenomenon during incremental fabrication by the laser sintering process, which increase the contact area and bond strength by creation of undercuts (EunJeong 2014) and (Gu D 2007).

The fact that all tested samples in our study yielded higher bond strength than the minimum strength required by IS09693:1999(E), which is 25 MPs shows that the alloy fabricated by the SLM technique can not only provide an acceptable bond for clinical application, it even yields higher bond strength than the casting method. Akova and Serra-Prat in separate studies showed that despite higher bond strength of the casting group, the difference between the casting and SLM techniques did not reach statistical significance (Serra-Prat 2014). Controversy between their results and ours may be attributed to the different form of samples (cylindrical) and assessment of shear bond strength instead of flexural bond strength.

Xiang and Ren found no significant difference in bond strength of the SLM and casting groups; although the values obtained in the SLM group were higher in both studies (Xiang 2012). Difference between their results and ours may be due to difference in the load application speed for flexural test, difference in laser system and composition of alloys used and size of sandblasting particles.

Inspection of the surface of samples in the SLM group before porcelain applying revealed that the surface of bars in the SLM group was dark gray and had no metal shine in our study. The reason may be that the metal powder particles are fused on the surface of components fabricated by the SLM method; thus, the samples show a color similar to that of metal powder particles.

Visual observation of each sample during the flexural strength testing revealed that the debonding cracks at 
the metal-ceramic interface occurred at one end of the ceramic layer and not at the center of it, which was in agreement with IS09693:1999(E) standards. Evaluation of surface morphology of metal matrix after porcelain debonding showed that the color was different at the center and at the ends of the samples. This indicated that the ceramic layer was still present on the entire surface of samples. Moreover, mode of metal-ceramic debonding may indicate the fracture energy that degrades the metal-ceramic bond. The higher the amount of porcelain body remaining on the metal surface, the higher the adhesion of porcelain body to metal, the higher the fracture energy and the lower the risk of porcelain fracture would be in the clinical setting (Wagner 1993) and (Lavine 1966). Five samples in the SLM group showed cohesive failure while in the casting group, all fractures were mixed. The reason is probably the higher bond strength of the SLM group. Since after debonding high amounts of porcelain remained on the alloy surface, it may be concluded that a strong bond was created between dental porcelain and SLM alloy at the interface. Thus, this technique can increase the success rate of porcelain fused to metal restorations.

Since this study had an in vitro design, the SLM alloy should also be evaluated in the oral cavity. Also, it is recommended to assess the marginal fit of copings fabricated by this technique. The bonding interface should be evaluated using scanning electron microscope and energy-dispersive X-ray spectroscopy in future studies. The microstructure of SLM alloy must also be analyzed under a metallographic microscope.

\section{CONCLUSION}

The SLM alloy system not only provides a clinically acceptable bondstrength , the bond strength of restorations fabricated by this method to porcelain was even higher than that of restorations fabricated by the conventional casting method. Thus, this relatively new technology can serve as an alternative to the conventional casting method for the fabrication of metal-ceramic restorations.

\section{ACKNOWLEDGEMENTS}

The work described in this paper has been retrieved from Dr. ParisaAlirezaii'sthesis. The authors would like to thank Dr. MarziehMahmoodi for useful statistical consultations.

\section{REFERENCES}

Abduo, J. and Lyons, K.M., 2017. Interdisciplinary interface between fixed prosthodontics and periodontics. Periodontology 2000, 74(1), pp.40-62.
Akova, T., Ucar, Y., Tukay, A., Balkaya, M.C. and Brantley, W.A., 2008. Comparison of the bond strength of laser-sintered and cast base metal dental alloys to porcelain. dental materials, 24(10), pp.1400-1404.

Bae, E.J., Kim, J.H., Kim, W.C. and Kim, H.Y., 2014. Bond and fracture strength of metal-ceramic restorations formed by selective laser sintering. The journal of advanced prosthodontics, 6(4), pp.266-271.

Bagby, M., Marshall, S.J. and Marshall, G.W., 1990. Metal ceramic compatibility: a review of the literature. The Journal of prosthetic dentistry, 63(1), pp.21-25.

Bhaskaran, E., Azhagarasan, N.S., Miglani, S., Ilango, T., Krishna, G.P. and Gajapathi, B., 2013. Comparative Evaluation of Marginal and Internal Gap of $\mathrm{Co}-\mathrm{Cr}$ Copings Fabricated from Conventional Wax Pattern, 3D Printed Resin Pattern and DMLS Tech: An In Vitro Study. The Journal of Indian Prosthodontic Society, 13

Bowers, J.E., Vermilyea, S.G. and Griswold, W.H., 1985. Effect of metal conditioners on porcelain-alloy bond strength. The Journal of prosthetic dentistry, 54(2), pp.201-203.

(3), pp.189-195.

Brocker, C.N., 2012. Characterization of aldehyde dehydrogenase 7A1 (ALDH7A1) and the potential mechanisms underlying pyridoxine-dependent epilepsy (Doctoral dissertation, University of Colorado at Denver).

Chung, K.H. and Hwang, Y.C., 1997. Bonding strengths of porcelain repair systems with various surface treatments. The Journal of prosthetic dentistry, 78(3), pp.267-274.

Daftary, F. and Donovan, T., 1986. Effect of four pretreatment techniques on porcelain-to-metal bond strength. The Journal of prosthetic dentistry, 56(5), pp.535-539.

Drummond, J.L., Randolph, R.G., Jekkals, V.J. and Lenke, J.W., 1984. Shear testing of the porcelain-metal bond. Journal of dental research, 63(12), pp.1400-1401.

Gu, D. and Shen, Y., 2007. Balling phenomena during direct laser sintering of multi-component $\mathrm{Cu}$-based metal powder. Journal of Alloys and Compounds, 432(1), pp.163-166.

Huang, Z., Zhang, L., Zhu, J. and Zhang, X., 2015. Clinical marginal and internal fit of metal ceramic crowns fabricated with a selective laser melting technology. The Journal of prosthetic dentistry, 113(6), pp.623-627.

Jing-min, L.I., Wei-qian, W.A.N.G. and Jing-yuan, M.A., 2014. Comparison of the clinical effects of selective laser melting deposition basal crowns and cobalt chromium alloy base crowns. Shanghai Journal of Stomatology, 23(3).

Jochen, D.G., Caputo, A.A. and Matyas, J., 1986. Effect of metal surface treatment on ceramic bond strength. The Journal of prosthetic dentistry, 55(2), pp.186-188.

Kaleli, N. and Saraç, D., 2017. Comparison of porcelain bond strength of different metal frameworks prepared by using conventional and recently introduced fabrication methods. The Journal of Prosthetic Dentistry.

Kelsey 3rd, W.P., Latta, M.A., Stanislav, C.M. and Shaddy, R.S., 1999. Comparison of composite resin-to-porcelain bond 
strength with three adhesives. General dentistry, 48(4), pp.418421.

Kukiattrakoon, B., Hengtrakool, C. and Kedjarune-Leggat, U., 2010. Chemical durability and microhardness of dental ceramics immersed in acidic agents. ActaOdontologicaScandinavica, 68(1), pp.1-10.

Lavine, M.H. and Custer, F., 1966. Variables affecting the strength of bond between porcelain and gold. Journal of dental research, 45(1), pp.32-36.

Lenz, J., Schwarz, S., Schwickerath, H., Sperner, F. and Schäfer, A., 1995. Bond strength of metal-ceramic systems in threepoint flexure bond test. Journal of Applied Biomaterials, 6(1), pp.55-64.

Liu, Y., Wang, Z., Gao, B., Zhao, X., Lin, X. and Wu, J., 2010. Evaluation of mechanical properties and porcelain bonded strength of nickel-chromium dental alloy fabricated by laser rapid forming. Lasers in medical science, 25(6), pp.799804.

Nair, S.J., Hegde, V. and Vallabhaneni, T.T., 2016. Effect of multiple firings on shear bond strength of feldspathic porcelain to base metal alloys: an in-vitro study. Indian Journal of Dental Advancements, 8(2), pp.89-94.

Örtorp, A., Jönsson, D., Mouhsen, A. and von Steyern, P.V., 2011. The fit of cobalt-chromium three-unit fixed dental prostheses fabricated with four different techniques: A comparative in vitro study. Dental Materials, 27(4), pp.356-363.

Quante, K., Ludwig, K. and Kern, M., 2008. Marginal and internal fit of metal-ceramic crowns fabricated with a new laser melting technology. Dental Materials, 24(10), pp.1311-1315.

Pameijer, C.H., LOUW, N.P. and FISCHER, D., 1996. Repairing fractured porcelain: how surface preparation affects shear force resistance. The Journal of the American Dental Association, 127(2), pp.203-209.

Pavlović, V.B., Vulićević, Z. and Pavlović, V.P., 2017. Contemporary Dental Ceramics. In Proceedings of the IV Advanced Ceramics and Applications Conference (pp. 95-119). Atlantis Press, Paris.

Pittayachawan, P., McDonald, A., Petrie, A. and Knowles, J.C., 2007. The biaxial flexural strength and fatigue property of Lava $^{\mathrm{TM}}$ Y-TZP dental ceramic. dental materials, 23(8), pp.10181029.
Serra-Prat, J., Cano-Batalla, J., Cabratosa-Termes, J. and Figueras-Àlvarez, 0., 2014. Adhesion of dental porcelain to cast, milled, and laser-sintered cobalt-chromium alloys: shear bond strength and sensitivity to thermocycling. The Journal of prosthetic dentistry, 112(3), pp.600-605.

Sudsangiam, S. and van Noort, R., 1999. Do dentin bond strength tests serve a useful purpose?.Journal of Adhesive Dentistry, 1(1).

The International Organization for Standardization. Metalceramic systems. ISO 9693-1: 2012(E):1-4.

Wagner, W.C., Asgar, K., Bigelow, W.C. and Flinn, R.A., 1993. Effect of interfacial variables on metal-porcelain bonding. Journal of Biomedical Materials Research Part A, 27(4), pp.531-537.

Walton, J.N., Gardner, F.M. and Agar, J.R., 1986. A survey of crown and fixed partial denture failures: length of service and reasons for replacement. The Journal of prosthetic dentistry, 56(4), pp.416-421.

Wu, L., Zhu, H., Gai, X. and Wang, Y., 2014. Evaluation of the mechanical properties and porcelain bond strength of cobaltchromium dental alloy fabricated by selective laser melting. The Journal of prosthetic dentistry, 111(1), pp.51-55.

Xiang, N., Xin, X.Z., Chen, J. and Wei, B., 2012. Metal-ceramic bond strength of $\mathrm{Co}-\mathrm{Cr}$ alloy fabricated by selective laser melting. Journal of dentistry, 40(6), pp.453-457.

Xin, X.Z., Xiang, N., Chen, J., Xu, D. and Wei, B., 2012. Corrosion characteristics of a selective laser melted $\mathrm{Co}-\mathrm{Cr}$ dental alloy under physiological conditions. Journal of Materials Science, 47(12), pp.4813-4820.

Zhang, S., Li, Y., Hao, L., Xu, T., Wei, Q. and Shi, Y., 2014. Metalceramic bond mechanism of the Co-Cr alloy denture with original rough surface produced by selective laser melting. Chinese Journal of Mechanical Engineering, 27(1), pp.69-78.

Zhukovsky, L., Godder, B., Settembrini, L. and Scherer, W. 1996. Repairing porcelain restorations intraorally: techniques and materials. Compendium of continuing education in dentistry (Jamesburg, NJ: 1995), 17(1), pp.18-20.

Zinelis, S., Tsetsekou, A. and Papadopoulos, T., 2003. Thermal expansion and microstructural analysis of experimental metalceramic titanium alloys. The Journal of prosthetic dentistry, 90(4), pp.332-338. 